\title{
IMPACTS OF UNATTENDED TRAIN OPERATIONS (UTO) ON PRODUCTIVITY AND EFFICIENCY IN METROPOLITAN RAILWAYS
}

\section{Judith M. Cohen*, Alexander S. Barron, Richard J. Anderson, and Daniel J. Graham}

Railway and Transport Strategy Centre, Centre for Transport Studies, Dept. of Civil and Environmental Engineering, Imperial College London, London, United Kingdom SW7 2AZ

\section{Corresponding author: Judith M. Cohen}

Railway and Transport Strategy Centre, Centre for Transport Studies, Dept. of Civil and Environmental Engineering, Imperial College London, London, United Kingdom SW7 2AZ E-mail: judith.cohen@imperial.ac.uk

Tel: +44 (0)20 75943486

\section{Alexander S. Barron}

Railway and Transport Strategy Centre, Centre for Transport Studies, Dept. of Civil and Environmental Engineering, Imperial College London, London, United Kingdom SW7 2AZ E-mail: alexander.barron@imperial.ac.uk

\section{Richard J. Anderson}

Railway and Transport Strategy Centre, Centre for Transport Studies, Dept. of Civil and Environmental Engineering, Imperial College London, London, United Kingdom SW7 2AZ E-mail: richard.anderson@imperial.ac.uk

\section{Daniel J. Graham}

Railway and Transport Strategy Centre, Centre for Transport Studies, Dept. of Civil and Environmental Engineering, Imperial College London, London, United Kingdom SW7 2AZ E-mail: d.j.graham@imperial.ac.uk

SUBMISSION DATE: $1^{\text {st }}$ August 2014

REVISED SUBMISSION: $14^{\text {th }}$ November 2014

FINAL REVISION FOR PUBLICATION: $13^{\text {th }}$ March 2015

WORD COUNT: 7444

Tables: (0) 0

Figures: (7) 1750

Abstract: 227

Text: 4738

References: 729 


\begin{abstract}
Urban metro subway systems (metros) around the world are choosing increasing levels of automation for new and existing lines: the global length of metro lines capable of unattended train operation (UTO) is predicted to triple in the next ten years. Despite significant investment in this technology, empirical evidence for the financial and service quality impacts of UTO in metros remains scarce.

We used questionnaires and semi-structured interviews with metros of the CoMET and Nova benchmarking groups to assemble emerging evidence for how automation affects costs, staffing, service capacity and reliability.

Data from 23 lines suggest that UTO can reduce staff numbers by $30-70 \%$, with the amount of wage cost reduction depending on whether staff on UTO lines are paid more. Based on the experience of seven metros, capital costs of lines capable of unattended operation are higher, but internal rate of return has been estimated by two metros at $10-15 \%$. Automated lines are capable of operating at the highest service frequencies of up to 42 trains per hour, and the limited available data suggest that automated lines are more reliable.

Our findings indicate that UTO is a means to a more flexible and reliable operating model that can increase metro productivity and efficiency. We identify important work that is needed to better understand impacts, identifying where statistical analyses will add value once sufficiently large datasets become available.
\end{abstract}




\section{INTRODUCTION}

Globally, the use of Unattended Train Operations (UTO) in urban metro subway systems (metros) is a growing trend. From 2005-2013, the global length of UTO-capable metro lines grew from $\sim 300 \mathrm{~km}$ to $674 \mathrm{~km}$, and is expected to grow to $1800 \mathrm{~km}$ by 2025 (1). For metro owners, project sponsors and funders, it is essential to optimise use of funds from fare and tax payers. Any investment in UTO technology must therefore be assessed in terms of maximising metro productivity and efficiency. Crucially, how much is the additional capital cost of the more advanced equipment, and is it justified by benefits to operating costs and/or the capacity and reliability of service?

There is a dearth of academic literature systematically assessing the effects of UTO, so the knowledge gap has been filled by conferences $(2,3)$ and magazines (4-6). This literature tends to be based on general concepts (4), or the detailed experience of one metro $(2,3,6)$. Academic knowledge is limited by a lack of global, comprehensive investigation of the technology using comparable data from multiple metros.

This study contributes emerging evidence collected for the CoMET and Nova urban metro benchmarking groups towards understanding the cost and operational implications of UTO. Four specific research questions address how automation might affect various elements of metro productivity and efficiency as follows:

- What is the additional capital cost of technology that enables UTO?

- Assuming a constant number of stations and trains in service, what level of staffing is required on a UTO line compared with a conventional one?

- How is the operational cost of a UTO line different to a conventional line (including effects related to staffing)?

- How does UTO affect metro service outputs such as capacity and reliability?

This paper begins by establishing key terminology in Section 2. Section 3 reviews literature regarding potential contributions of automation to metro efficiency and productivity. Section 4 describes the research method and data. Section 5 presents and discuses results, and finally Section 6 draws conclusions, identifying opportunities for future analysis as the global prevalence of UTO increases.

\section{TERMINOLOGY}

Discussion of 'automated operations' has involved a confusing array of terminology. In particular, the word 'driverless' reads as a synonym for 'unattended' but is elsewhere defined as referring to trains that do not have a driver's cab but do require on-board staff (7), creating potential for confusion. The International Electrotechnical Commission (IEC) standard IEC62290 (8) has defined clear terminology to classify the Grade of Automation (GoA) of a metro, whereby:

- GoA1 has automatic train protection (ATP) and is manually driven.

- GoA2 has automatic train operation (ATO) with a driver in a cab performing critical functions such as closing doors and starting the train in motion.

- GoA3 has ATO and a train attendant in the passenger car performing a critical function such as supervising safe door closure.

- GoA4 is capable of unattended train operation (UTO). 
A glossary explaining ATP and ATO in more detail is included at the end of this paper.

Based on observations of metros, we identified a significant operational variant whereby a GoA4 system is operated with attendants on board every train, even though the system's technical design does not require on-board staff. IEC-62290 is clear that the GoA terminology describes the system capability, not the operational model. Thus GoA4 systems can be operated either unattended (UTO); or with an attendant on board. Unlike in a GoA3 system, the attendant in this scenario is not essential to the functioning of the train. This operational model is referred to in this paper as "attended GoA4", to describe both the underlying system capability and the way it is operated. The flowchart in FIGURE 1 illustrates the defining features of the different operational models.

FIGURE 2 shows how these operational models relate to other common terminology. The figure is adapted from IEC-62290 solely for the purposes of demonstrating the operational differences in the application of the formal categorisation in the standard. Throughout this paper, lines are referred to by their operational model, and GoA3 and above are collectively referred to as 'automated lines.' We recommend that the term 'driverless' is not used, as it does not clearly distinguish between GoA3, attended-GoA4, or UTO, all of which involve trains operating without traditional drivers.

\section{LITERATURE REVIEW}

\section{The productivity and efficiency of metros}

Anderson et al indicated that a majority of metros studied received a public subsidy for operations (9). To ensure value for public funds, metros must try to optimise productivity, the absolute ratio of inputs to outputs; and efficiency, the relationship between actual outputs and maximum possible outputs. Coelli et al (10) note that the maximum possible productivity (the production frontier) changes over time as a result of technical development. Automation of metro systems to enable UTO is one such technical development which may increase the production frontier.

Metro efficiency has been assessed for individual (11) and multiple metros (12), but without identifying the impact of particular technical characteristics such as automation. Quddus et al (13) investigated factors affecting station operating costs, but to our knowledge no similar study has assessed factors affecting the efficiency of train service operations.

\section{Productivity and efficiency benefits of automation}

\section{Metro staff and productivity}

Couto and Graham (14) in a study of European mainline railways identified staff per trainkilometre as an important determinant of cost inefficiency. Andreau and Ricart (15) deduced that organisational efficiency of metros is closely linked to availability and scheduling of drivers. Thus UTO has the potential to improve efficiency. Andreau and Ricart also observed that even GoA2 can simplify tasks, such that each individual staff member can learn more tasks and perform a more multi-skilled role, which could also increase efficiency (15).

Several studies have shown that increasing train frequency increases demand (16-18). Therefore, operating trains of half the length at twice the frequency should increase ridership 
with only marginally increased traction energy cost. The barrier to doing this on conventional lines is that driver costs would double. On UTO lines there is no additional driver cost, which could enable this demand-generative strategy.

Technical requirements for substitution of labour by automation in GoA4 metros has received some coverage from a systems and technical perspective $(19,20)$, but systematic research investigating the effects on staff numbers (and staff costs) does not appear to be available. Paris Métro reports operational costs 30\% lower for UTO than for conventional lines (21). Another operator (and supplier) of UTO systems, Keolis, estimates operational cost savings of $10 \%$ due to staff reductions (22).

\section{Efficient use of infrastructure}

In addition to reducing labour inefficiencies, automation can enable better use of available infrastructure. For example, GoA2 and above can enable higher operational speeds and train frequencies due to Automatic Train Operation (ATO) (21, 23). Paris Métro has reported that after upgrading from GoA1 to GoA4, Line 1 requires fewer rolling stock units to provide the same level of service (21). Additionally, removal of the driver's cab provides more physical space within the train, which in Paris Métro Line 1 added 6\% to capacity (21).

There is evidence that increasing the level of automation improves reliability: switching from manual to automatic operation (from GoA1 to GoA2 or above) is associated with a $33 \%$ reduction in 5 minute delay incidents (23). However this study had insufficient data points available to disaggregate GoA2, GoA3 and GoA4. Reasons that GoA4 could improve reliability include removal of 'driver unavailable' as a reason for cancelled trains $(15,23)$, and reduced opportunity for incidents caused by human error $(23,24)$. Reliability affects both train-km and passenger-km outputs. Preston et al (25) show that long term unreliability can reduce passenger numbers, reducing metro effectiveness.

Commercial data suggest that GoA4 lines achieve very high levels of reliability. The supplier and operator Keolis claims availability for unattended systems is $99 \%$ to $99.99 \%$, compared with $96-98 \%$ for driven systems (22). It is unclear whether Keolis' data refer to system availability (counting signalling faults only) or service availability (including disruptions of any cause). Dubai Metro has reported service availability of $99.97 \%$ (3). It is important to note that these data were reported by organisations with a vested interest in presenting GoA4 systems as highly reliable. Additionally, although these figures are all presented as percentages and so appear superficially comparable, their sources did not detail the method used to calculate the data, so it is not possible to judge whether consistent methods were used. Thus comparisons between these sources may not be valid. Comparing reliability of automated and conventional lines using a consistent measurement definition, validated over a number of years of data collection, will therefore be a new contribution.

\section{METHOD}

In 2013, automated metros accounted for $6 \%$ of the world's metro line kilometres $(1,26)$. Metros operating both automated and conventional lines (enabling direct comparison) are more rare. Because benchmarking is a systematic process of "comparing, and understanding 
organisations 'performance and change in performance" (27) it is an appropriate approach in this situation as it can be undertaken without large sample sizes.

This paper represents outputs from what is defined by the European Commissionfunded EQUIP project (28) as the highest level of benchmarking, defined by exchange of confidential information, and direct engagement between companies to learn good practices and how improvements are implemented. The CoMET and Nova benchmarking groups are noted among the few organisations engaging in this level of benchmarking among public transport operators (12).

\section{Benchmarking staffing}

Previous studies have assessed staffing levels in terms of staff per train-kilometre (14). Scoping questions revealed that participating metros were not able to disaggregate staff per train-km by line. We therefore developed the 'staff per asset' measure as a way to normalise staffing levels according to the number of trains in service (service level) and the number of stations (as stations are the main driver of off-train staffing, and also a proxy for line length). The total number of operational staff working in the peak hour was divided by the total number of assets (trains and stations) in service. 'Operational staff' included those based in control centres, in stations, on trains, and roaming between stations and trains. This accounted for equivalence between roaming staff on a UTO line and train or station staff on a conventional line. Control centre staff were included to account for any substitution of linebased staff for control centre staff on a UTO line.

\section{Data}

This study used data supplied by the CoMET and Nova benchmarking consortia of 32 metro system operators. ${ }^{1}$ Of these, ten metros operate automated lines - defined for this purpose as lines which do not have a traditional driver in a cab: GoA3 or GoA4. Twelve metros within the group are planning to build new or convert existing lines for automated operations in the future. Because of the small number of automated lines operated by CoMET and Nova members, six additional metros were invited to participate in the study, of which three participated: Copenhagen Metro, Milan Metro (Line 5), and Vancouver SkyTrain.

A confidentiality agreement enabled the provision of data, but means research results must be anonymised for publication. Therefore, metros are identified throughout by operational model or by continent, as appropriate.

A questionnaire and semi-structured interviews were used to obtain data to understand how automated and conventional lines differ in terms of:

- Additional capital expenditure

- Difference in operational expenditure (including maintenance expenditure)

- Staff numbers and operational staffing models

- Capacity (trains per hour)

- Reliability (mean distance between failures)

\footnotetext{
${ }^{1}$ CoMET - large metros: Beijing, Berlin, Guangzhou, Hong Kong, London, Mexico City, Madrid, Moscow, New York, Paris Métro and RER, Santiago, Shanghai, Singapore, São Paulo and Taipei;

Nova - medium and small metros: Bangkok, Barcelona, Buenos Aires, Brussels, Delhi, Docklands Light Railway (London), Istanbul, Kuala Lumpur, Lisbon, Montréal, Nanjing, Naples, Newcastle, Rio de Janeiro, Toronto and Sydney
} 
Responses were received for 11 existing and 10 planned GoA4 lines, and 2 existing GoA3 lines. Of the existing GoA4 lines, three are attended-GoA4, and the other eight are UTO. Semi-structured interviews were undertaken with metros currently operating a UTO line. All responses were followed up with data verification and clarification questions.

In addition to data collected specifically for this study, we used existing CoMET and Nova benchmarking data, which benefits from many years of refined definitions and data validation. This included reliability data as described by Melo et al (23) and station dwell time and service regularity survey data as described by Harris and Anderson (29).

\section{RESULTS AND DISCUSSION}

\section{Capital Cost}

Metros were asked what technology was considered absolutely necessary to enable UTO. Four features were reported by every respondent:

- Capability to remotely control trains;

- Remote monitoring and reset of rolling stock systems;

- Two-way communications between operations control centre (OCC) and train; and

- A platform edge safety system, which could be either an intrusion detection system or platform doors.

FIGURE 3 illustrates the 'additional' costs of GoA4 equipment, as reported by seven metros (labelled by continent). We found that the "additional cost" for GoA4 depends on the baseline to which equipment is being compared - the technologies and capabilities used by a metro's existing conventional systems. These vary widely. For instance, Asian metros tend to install platform doors as standard, so in Asia platform doors are not considered 'additional' for GoA4. Similarly, some metros have very basic standard rolling stock , as is the case for the metro that reported a $20 \%$ uplift in rolling stock cost for GoA4. In other metros, including two that reported additional costs as 'not significant,' the standard train for conventional lines already includes the advanced passenger information systems and remote condition monitoring capabilities that would be specified for GoA4.

Even within GoA4, different capabilities may be specified. For example, an OCC with full remote control of stations as well as trains would cost more than one that can only remotely control trains. It is also important to note that rolling stock costs vary much more for reasons other than the difference between GoA2 and GoA4 specifications. Two metros reported rolling stock of similar specification varying in price by almost $40 \%$ depending on the number ordered or the supplier.

Two metros had calculated the Internal Rate of Return (IRR) of UTO prior to implementation. IRR illustrates the yield of an investment, so an IRR higher than the cost of capital indicates a desirable investment. Compared with a GoA2 baseline, a European metro estimated IRR at $12-15 \%$, equivalent to a 10-year return on investment. An Asian metro estimated IRR of $>10 \%$ for UTO compared with attended-GoA4, assuming that the change from attended-GoA4 to UTO involved a 50\% reduction in on-train staff.

\section{Operational Cost}


Consistent data regarding how different elements of operational cost are directly affected by UTO were not available. Overall, operating costs may be affected mainly by staff and maintenance cost differences, but metros were unable to disaggregate these costs between automated and conventional lines.

Anecdotal evidence from two metros indicates that it is not possible to translate staffing levels directly to operational costs, because multi-skilled staff on UTO lines may be paid more than drivers or station staff on conventional lines. Wage cost changes would depend on a metro-specific decision about headcount reduction and any average wage increase. However, de-linking the number of trains from the number of drivers does reduce the role of staff costs in limiting service frequency increase - meaning that traction energy consumption would become the key operational cost constraint. Two metros reported they chose to procure a UTO system with shorter trains rather than a conventional system, with the intention to operate the same total car-km but using shorter trains at higher frequencies. This strategy is demand-generative, minimising traction energy consumption whilst providing better value than a longer-train, lower-frequency solution.

Maintenance cost effects were also unquantifiable. One European and two Asian metros reported that remote condition monitoring and equipment redundancy reduce the amount of preventive maintenance that needs to be done on GoA4 lines, but also noted that spare parts are more expensive. In two metros where maintenance costs for automated and conventional lines were different, organisational or technological confounding factors make it impossible to distinguish the cause of the difference.

\section{Staffing models}

Staff information was provided for sixteen existing and seven planned lines of all grades of automation. Four distinct staffing models were identified:

- Roaming multi-skilled staff only, with stations and trains mostly unattended (five GoA4 lines)

- Fixed station staff and roaming multi-skilled staff on some trains (seven GoA4 lines)

- Fully attended trains, with most stations unattended (two GoA3 lines)

- Fully attended trains and stations, as would typically be found on conventional lines (five Attended-GoA4, two GoA1 and two GoA2 lines)

Staff per asset was calculated to normalise for number of stations and trains in service. FIGURE 4 shows staff per asset for each line, indicating the staffing model and the grade of automation. The lowest staffing ratios are for lines with unattended stations as well as unattended train operations - an operating model which could be named Unattended Metro Operations - UMO. The wage-cost benefit to metros of adopting a fully automated operating model with automated trains and stations may lead metros planning automated lines to consider incorporating automated stations within the operating model as well.

FIGURE 5 illustrates the range of staffing ratios associated with different staffing models. The 'fully staffed' model of attended trains and stations had the widest range of staff per asset. Part of this variation is due to the larger sample size, but it also incorporated an unusually intensely staffed metro which has large numbers of platform staff to cope with extreme crowding. The majority of metros in the 'fully staffed' category were clustered closely around a staffing ratio of 1.4-1.6. The 'minimal' staffing model of unattended stations 
and trains was centred on 0.5-0.6 staff per asset. The data for both these staffing models are non-normally distributed, with skewiness values of 1.4 and 1.8 respectively. In both cases, the means are notably higher than the median due to the influence of outliers. The medians are therefore used as the basis for comparison. The 'minimal' staffing model has a median staffing ratio $70 \%$ less than that of the 'fully staffed' lines. The 'attended stations, unattended trains' model incorporated lines with high station staffing levels and those with only one staff member per station. The inter-quartile range therefore incorporates a high degree of variation in staffing models. The median staffing ratio for this operational model is $29 \%$ below that for the fully staffed lines.

A number of metros commented that, as hypothesised by Andreau and Ricart (15), UTO resulted in more multi-skilled roles for staff. One European metro reported that automated lines had lower absenteeism and attributed this to the increased diversity of tasks compared with driving.

\section{Service Outputs}

Capacity

Service Frequency In a set of service frequency data for 156 CoMET and Nova metro lines (including planned automated lines), a frequency of 30 trains per hour (tph) represented the fourth quintile and is considered a 'very high' frequency (FIGURE 6). The majority of existing and planned GoA4 lines are in this category, and the two highest-frequency lines at 42 tph are both GoA4. Very high frequencies are possible on conventional and automated systems - communications-based train control (CBTC) signalling systems are essentially the same for GoA2, GoA3 and GoA4. However, UTO can enable higher frequency by reducing turnaround times at the terminus. Improvements in frequency are also enabled by better regularity and consistency of station stop times: human factors can create variability and small delays in GoA2 and GoA3 lines (29).

Regularity Station dwell time and service regularity survey data were classified according to the grade of automation of the line, and interrogated for trends. Only 6 out of 66 available surveys related to GoA4 lines, so it is not possible to draw conclusions at this time. However, initial indications are that GoA4 operations may be associated with more consistent headways between trains, as indicated by a coefficient of variation (CofV) of 0.12 for headway regularity, compared with 0.28 for GoA2 lines and 0.36 for GoA1. A similar pattern for dwell time consistency showed CofV of 0.11 for GoA4, compared with 0.27 for GoA2 and 0.33 for GoA1.

These observations concur with one metro's finding that headway regularity on their automated line is $99.8 \%$, compared with $99.0 \%$ on their conventional lines. If headways are irregular, trains after a long gap are overcrowded, whilst a train following close behind another is much emptier so service quality suffers because more customers experience higher levels of crowding. Better regularity ensures that capacity provided is used efficiently and enables higher service frequency. 
Dwell times Dwell times are an important component of train frequency. On conventional lines, staff are typically responsible for initiating train dispatch and so determine the length of dwell times. On automatic lines, dwell times are programmed into the system. To account for random variation in passenger volumes and to reduce the risk of door holding, automated dwell times may be set longer than actual dwell times on conventional lines. In some cases, dwell times were deliberately lengthened: one metro extended dwell times from 45 to 60 seconds at interchanges because people were still trying to board the train after 45 seconds. Insufficient evidence is currently available to determine whether programmed dwell times necessarily need to be longer on a GoA4 line. However, even if GoA4 lines require slightly longer dwell times, improved consistency of those dwell times may more than offset potential capacity impacts. Platform doors almost always lead to increased dwell times because the larger doors take 1-2 seconds extra to open and close (29). However, platform doors are used as standard in many metros in Asia, and would be a drawback of automation only if not already used on conventional lines.

Cab removal The removal of the driver's cab has benefits for both capacity and also potentially costs. Prototype studies by a European metro indicated that a driver's cab took the equivalent space of 11 seats. A metro in the Americas estimates that the absence of cabs increases train capacity by $4-5 \%$. Procuring trains without cabs can have a cost-reducing effect: one European metro reported that trains without cabs were $1 \%$ cheaper than the equivalent with cabs.

\section{Flexibility}

GoA4 decouples train availability from staff availability. This enables better matching of capacity to demand, including adding service at short notice and low marginal cost. All metros with UTO lines named this flexibility as the key operational advantage of GoA4. One metro noted that on their GoA4 line they can add as many trains as needed for special events, rather than balancing extra service against cost. One European metro now needs one hour's notice rather than three months to schedule service for unusual events.

Attended-GoA4 systems are capable of temporarily operating unattended to prevent a delay caused by staff unavailability. This is a benefit of attended-GoA4 lines over GoA3 lines. One of the three attended-GoA4 metros occasionally operates a train unattended as needed to prevent a delay, and thus retains the flexibility of GoA4.

\section{Reliability}

Six GoA3 and GoA4 metro lines provided reliability data according to a common definition of Mean Distance (train-km) Between Failures causing an incidents lasting $\geq 5$ minutes (MDBF). As noted by Barron et al (30), passenger-focused metrics such as train and passenger delay hours are preferable, as response to some incidents on unattended lines may be prolonged if on-site intervention is required. Unfortunately, data of sufficient quality are generally not available for these measures. However, the MDBF data have been checked and verified according to a long-established definition developed by the CoMET and Nova benchmarking groups $(23,30)$. 
The automated lines all had reliability levels within the top third of CoMET and Nova network-wide averages (FIGURE 7). The two lines that had lower reliability than the rest of their networks, belong to two of the most reliable CoMET and Nova metros - and both lines have other technological differences from the rest of the metro that are unrelated to UTO. The automated lines in this analysis are all relatively new, so high reliability might be expected on account of equipment age. This is therefore an area where additional data in the future will enable more robust analysis.

\section{CONCLUSIONS}

This study has been the first to systematically assess the impacts of UTO using a global sample of metros. The findings indicate that GoA4 may have a higher capital cost than conventional and GoA3 lines, but that technologies required for GoA4 are increasingly being adopted for lower grades of automation - making the technological leap to GoA4 progressively smaller. Internal rates of return on investment in GoA4 reported by two metros were in the $10-15 \%$ region. Operational cost data availability was limited, and could be improved as part of more extensive line-level benchmarking across metros as a whole.

Staffing level data indicate that GoA4 can enable productivity and efficiency improvements. We developed the 'staff per asset' method of normalising line staffing levels, and showed that with the leanest staffing levels, UTO lines may have $70 \%$ fewer staff than conventional lines with staffed stations. On UTO lines where stations are staffed, headcount savings are around $30 \%$. These findings are practice-ready, enabling metro organisations to compare their staffing levels against those of their peers. We also found that GoA4 lines are not always operated unattended, identifying 'Attended-GoA4' as a distinct operating model.

GoA4 operations appear to enable a more regular service with more consistent stop times. This in turn enables high train frequencies up to $42 \mathrm{tph}$. GoA4 also enables increased operational flexibility to respond to delay incidents and unusual levels of crowding. Data for six automated lines showed them to have reliability equivalent to the top third of CoMET and Nova member metro networks. Future research will be able to compare reliability more robustly as the number of automated lines increases the availability of data, and there is a greater range of system ages.

\section{Study Limitations and Future Research}

This study was limited by the small available sample size, particularly for the assessment of reliability and of staffing levels. It is hoped that as the number of automated metros increases, it will be possible to study these issues in more detail with a larger dataset. In addition, several of the automated lines in this study were in their first few years of operation - with more years of operation there will be more data to analyse. Thus a key contribution of this study is identifying areas for deeper analysis in future. These include:

- Analysis of predicted versus actual capital and operating costs from the twelve CoMET and Nova metros planning to start operating an automated line in the next ten years.

- Econometric analysis of line-level operating cost data for metro lines of all grades of automation, to understand the impact of automation on operating cost. Ideally this dataset 
would include time-series data for metro lines being converted from conventional to automated.

- Examination of staffing levels on more metro lines, including conventional ones, to understand better the distribution of staff per asset levels within and between individual staffing models.

- Statistical analysis of association between Grade of Automation and reliability (MDBF), which will require more years of data from metros with both conventional and automated lines. Inclusion of line-level data for new conventional lines will enable like-for-like comparison of automated and conventional lines of similar age.

- Analysis to determine whether incidents on UTO lines have longer duration, as measured by train delay hours and/or passenger delay hours, which will require better data recording within metros to obtain these data according to a consistent definition and calculation method (30).

- Further dwell time surveys to determine whether the apparently better consistency of service regularity and station stop times on GoA4 lines is statistically significant.

\section{GLOSSARY}

GoA Grade of Automation, with grades 1 to 4 (see Section 2)

ATP Automatic Train Protection - automatic system which prevents unsafe movements but does not otherwise control the train.

ATS Automatic Train Supervision - system that regulates train service automatically

ATO Automatic Train Operation - train movement is controlled automatically, rather than manually by the driver.

UTO Unattended Train Operation - train operation with no staff member on board. UTO is only possible with a GoA4 system, but not all GoA4 systems are operated unattended.

UMO Unattended Metro Operations - metro operations without fixed staff in either trains or stations.

MDBF Mean Distance Between Failures - a technical measure of reliability

tph Trains per hour

\section{ACKNOWLEDGEMENT}

The authors wish to thank the CoMET and Nova member metros, and the metros of Copenhagen, Milan, and Vancouver, for their participation.

\section{REFERENCES}

1. UITP Observatory of Automated Metros, World Atlas Report. 2013, International Association of Public Transport (UITP).

2. Graham, I., Personnel care in an automated line - why we did it this way at SkyTrain, in 4th UITP Automated Metro Seminar. 2013: London.

3. Mohan, S. and S. Morrison, Creating a safe CBTC system without secondary detection, in 4th CBTC World Congress. 2013: London. 
4. Vuchic, V., Maintaining performance with full automation, in Metro Report International. 2014, DVV Group: Sutton. p. 36-39.

5. Horne, M., Driverless Underground trains for London?, in Modern Railways. 2012, Key Publishing Ltd. p. 62-65.

6. Serrallonga, C., New Staffing Model Captures the Benefits of an Automated Network. Metro Report: A Railway Gazette Yearbook, 2006. 162.

7. UITP Observatory of Automated Metros. Automation Essentials. 2014 [cited 2014 2014/03/04]; Available from: http://metroautomation.org/automation-essentials/.

8. International Electrotechnical Commission (IEC), IEC 62290-1: Railway applications: urban guided transport management and command/control systems. , in Part 1: system principles and fundamental concepts. 2006.

9. Anderson, R.J., N.S. Findlay, and D.J. Graham. Improving Fares and Funding Policies to Support Sustainable Metros. in Transportation Research Board 91st Annual Meeting. 2012.

10. Coelli, T., et al., An introduction to efficiency and productivity analysis. 2nd Ed. Springer, 2005.

11. Costa, A., Public Transport Efficiency and Effectiveness: Metro de Madrid. Transport networks in Europe: Concepts, analysis, and policies, 1998.

12. Santos, J., et al., Efficiency of the Portuguese metros. is it different from other European metros? 2010.

13. Quddus, M., N. Harris, and D.J. Graham, Metro Station Operating Costs: An Econometric Analysis. Journal of Public Transportation, 2007. 10(2).

14. Couto, A. and D.J. Graham, The determinants of efficiency and productivity in European railways. Applied Economics, 2009. 41(22): p. 2827-2851.

15. Andreau, R. and J.E. Ricart, Technology-Driven Organizational Innovation at the Barcelona Subway: Efficiency, Commitment, and Firm Boundaries, in 30th Annual Conference of the Strategic Management Society. 2010: Rome.

16. Graham, D.J., A. Crotte, and R.J. Anderson, A dynamic panel analysis of urban metro demand. Transportation Research Part E: Logistics and Transportation Review, 2009. 45(5): p. 787-794.

17. Litman, T., Valuing Transit Service Quality Improvements. Journal of Public Transportation, 2008. 11(2).

18. Paulley, N., et al., The demand for public transport: The effects of fares, quality of service, income and car ownership. Transport Policy, 2006. 13(4): p. 295-306.

19. Karvonen, H., et al., Hidden roles of the train driver: A challenge for metro automation. Interacting with Computers, 2011. 23(4): p. 289-298.

20. Wilson, J., et al., The railway as a socio-technical system: human factors at the heart of successful rail engineering. Proceedings of the Institution of Mechanical Engineers, Part F: Journal of Rail and Rapid Transit, 2007. 221(1): p. 101-115.

21. Ossent, T. Paris experience in driverless metro: increasing capacity, reducing costs. in MetroRail. 2010. London.

22. Leguay, P., Signalling, the way to improve performance: Bringing on automation functions to maximize capacity in a conventional operation, in UITP Automated Metro Seminar. 2013: London.

23. Melo, P.C., et al., Determinants of Delay Incident Occurrence in Urban Metros. Transportation Research Record: Journal of the Transportation Research Board, 2011. 2216(1): p. 10-18.

24. Seng, Y.K., et al. Automated metro-Ensuring safety and reliability with minimum human intervention. in Nineteenth annual international symposium of the international council on systems engineering (INCOSE). 2009. San Diego, CA, USA. 
25. Preston, J., et al., Impact of delays on passenger train services. Transportation Research Record: Journal of the Transportation Research Board, 2009. 2117(1): p. 1423.

26. International Association of Public Transport (UITP), World Metro Statistics 2013. 2013.

27. Trompet, M., R.J. Anderson, and D.J. Graham, Variability in comparable performance of urban bus operations. Transportation Research Record: Journal of the Transportation Research Board, 2009. 2111(1): p. 177-184.

28. EQUIP Consortium, The benchmarking handbook. Deliverable D4. European Commission DG-TREN and the EQUIP Consortium, Brussels and Newcastle upon Tyne, 2000.

29. Harris, N.G. and R.J. Anderson, An international comparison of urban rail boarding and alighting rates. Proceedings of the Institution of Mechanical Engineers, Part F: Journal of Rail and Rapid Transit, 2007. 221(4): p. 521-526.

30. Barron, A., et al., Passenger-Focused Management Approach to Measurement of Train Delay Impacts. Transportation Research Record: Journal of the Transportation Research Board, 2013. 2351: p. 46-53. 
JM Cohen*, AS Barron, RJ Anderson, \& DJ Graham

\section{LIST OF TABLES AND FIGURES}

FIGURE 1 Grade of Automation flowchart

FIGURE 2 Automated metro terminology

FIGURE 3 Additional capital cost of technology for a GoA4 system

FIGURE 4 Operational staff per asset during peak hour

FIGURE 5 Effect of staffing model on staff per asset

FIGURE 6 Frequencies of Automated Lines

FIGURE 7 Reliability of Automated Lines Compared with Whole Metro Networks 
JM Cohen*, AS Barron, RJ Anderson, \& DJ Graham

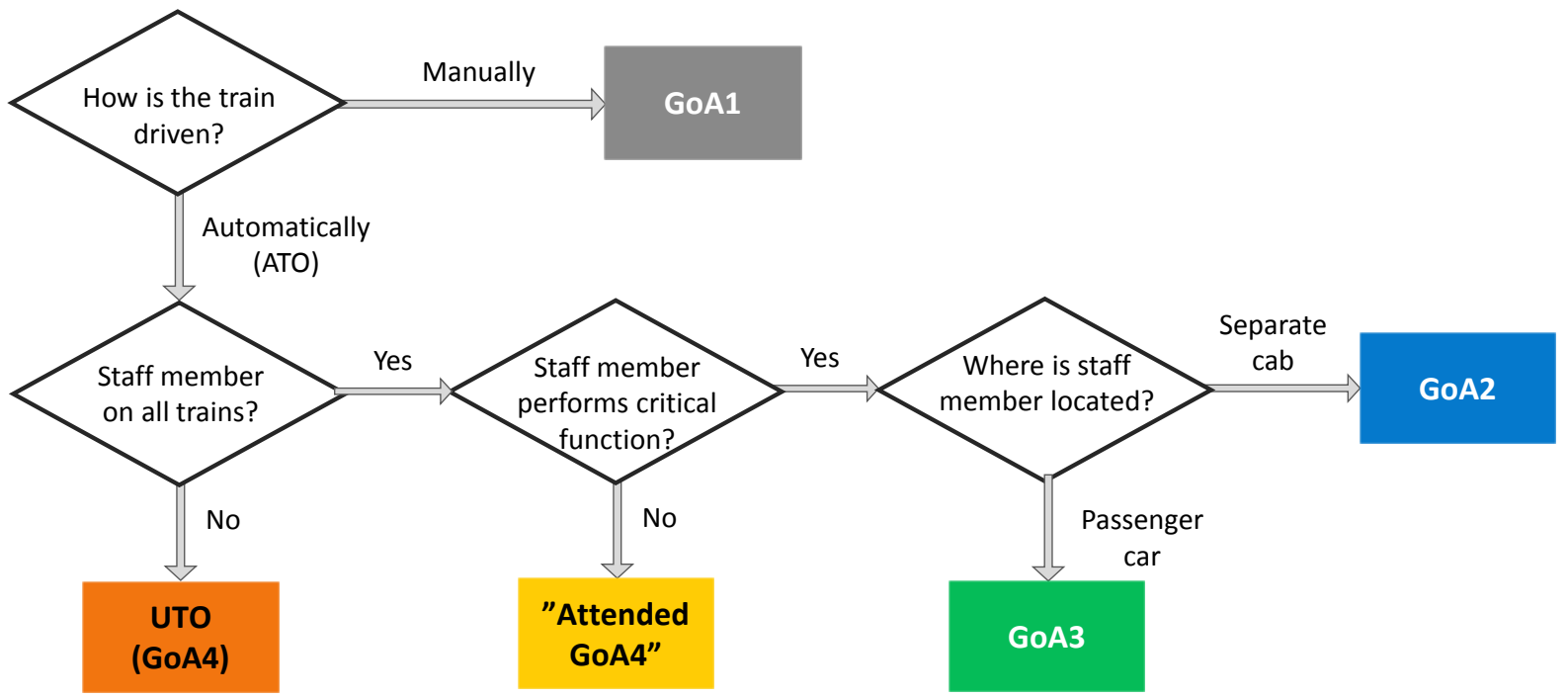

FIGURE 1 Flowchart relating operating models to grades of automation 


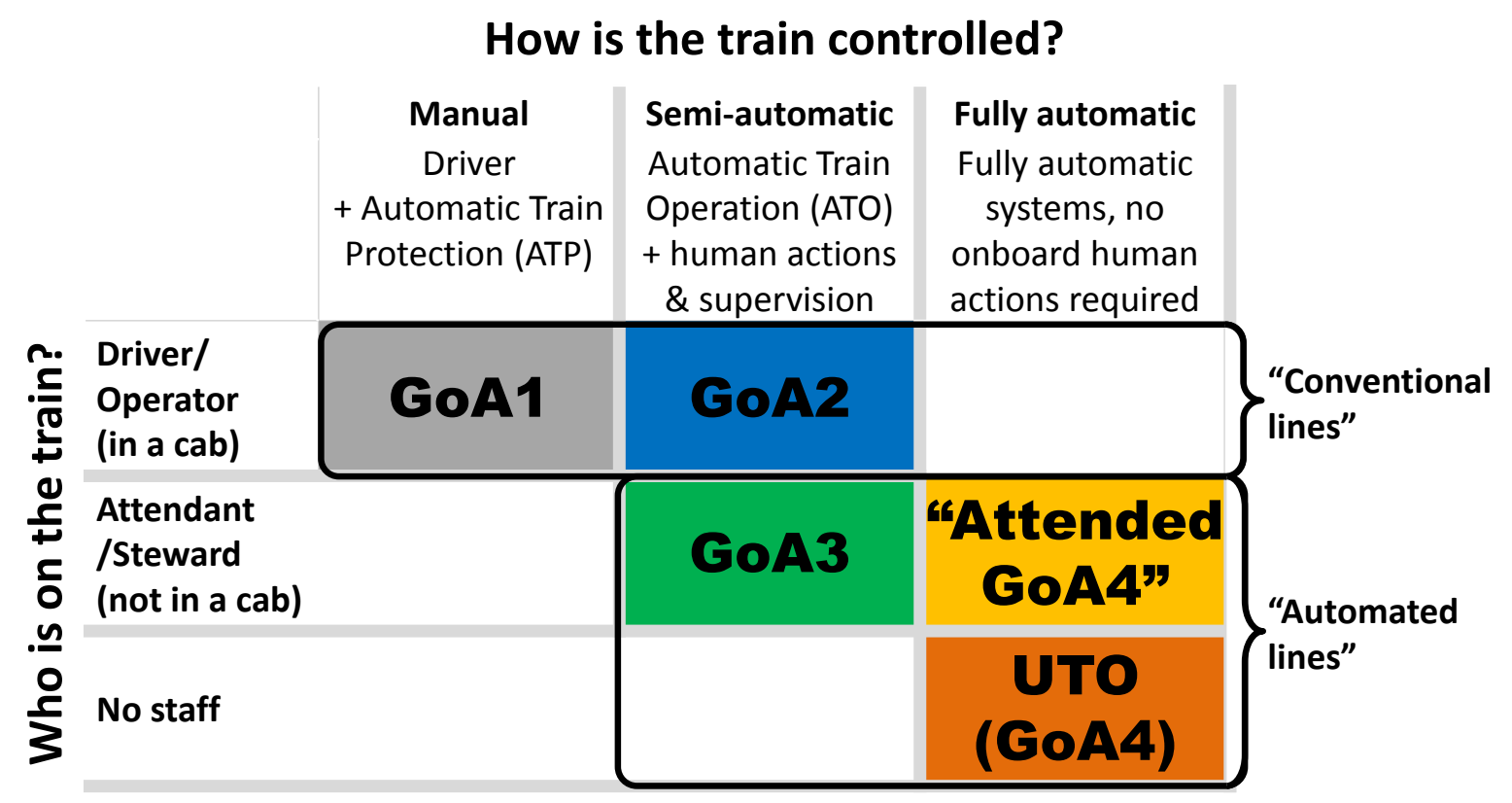

FIGURE 2 Schematic matrix clarifying the operational characteristics of different approaches to automation 
JM Cohen*, AS Barron, RJ Anderson, \& DJ Graham
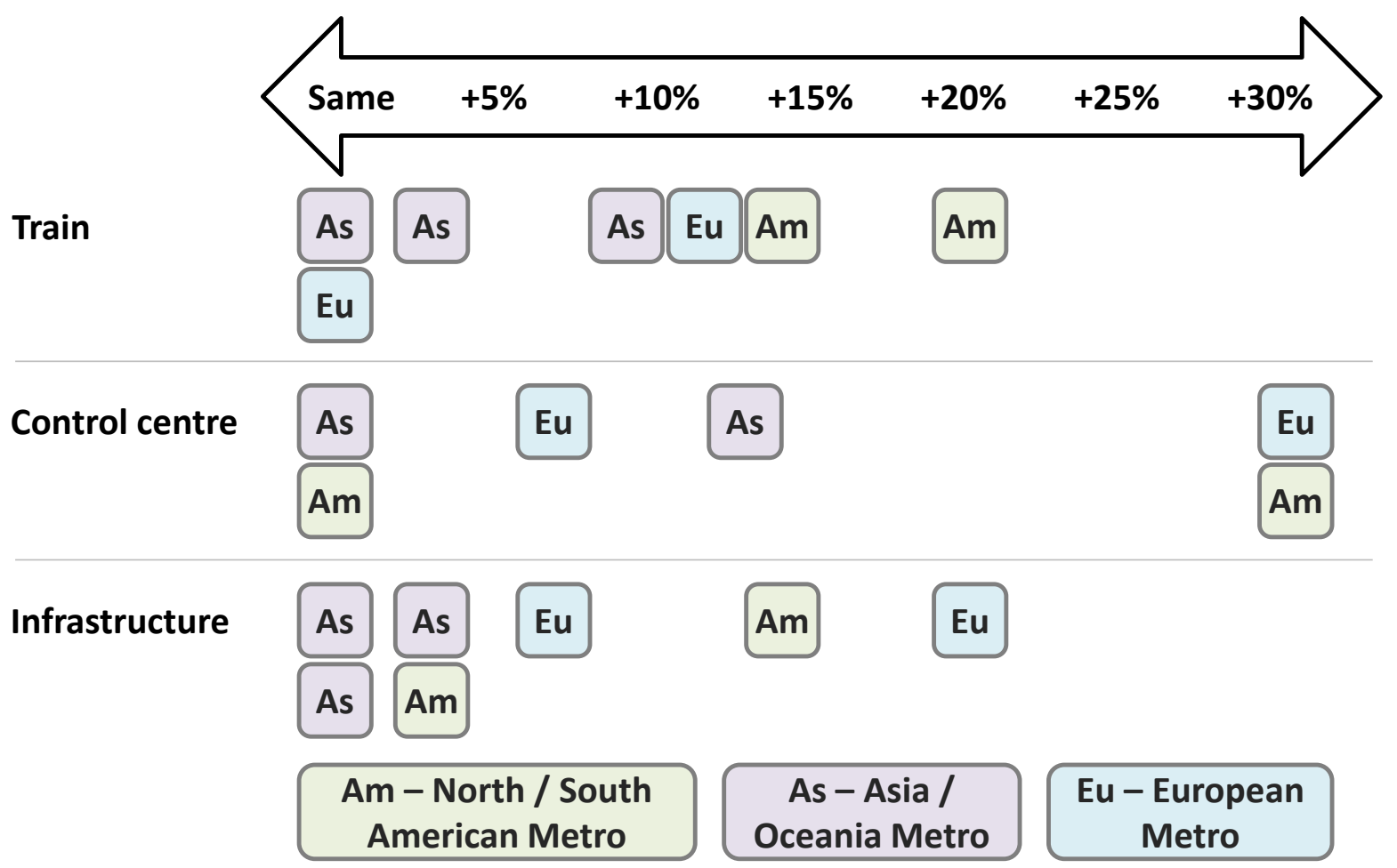

FIGURE 3 Additional capital cost of technology for a GoA4 system 
Operational staff (in trains, stations and control centre) per asset in service (stations + trains) during peak hour

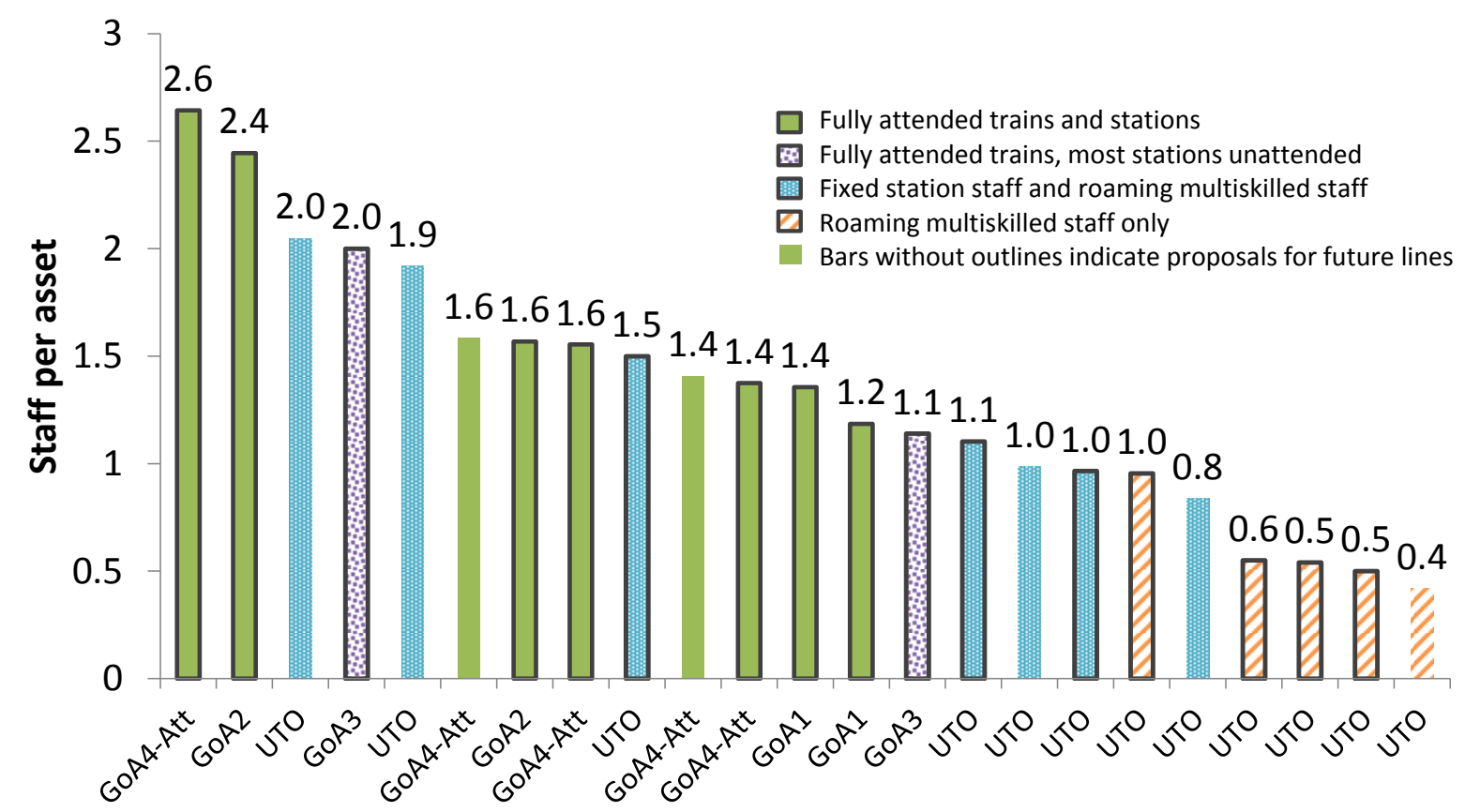

FIGURE 4 Operational staff per asset during peak hour 
Operational staff (in trains, stations and control centre) per asset in service (stations + trains) during peak hour

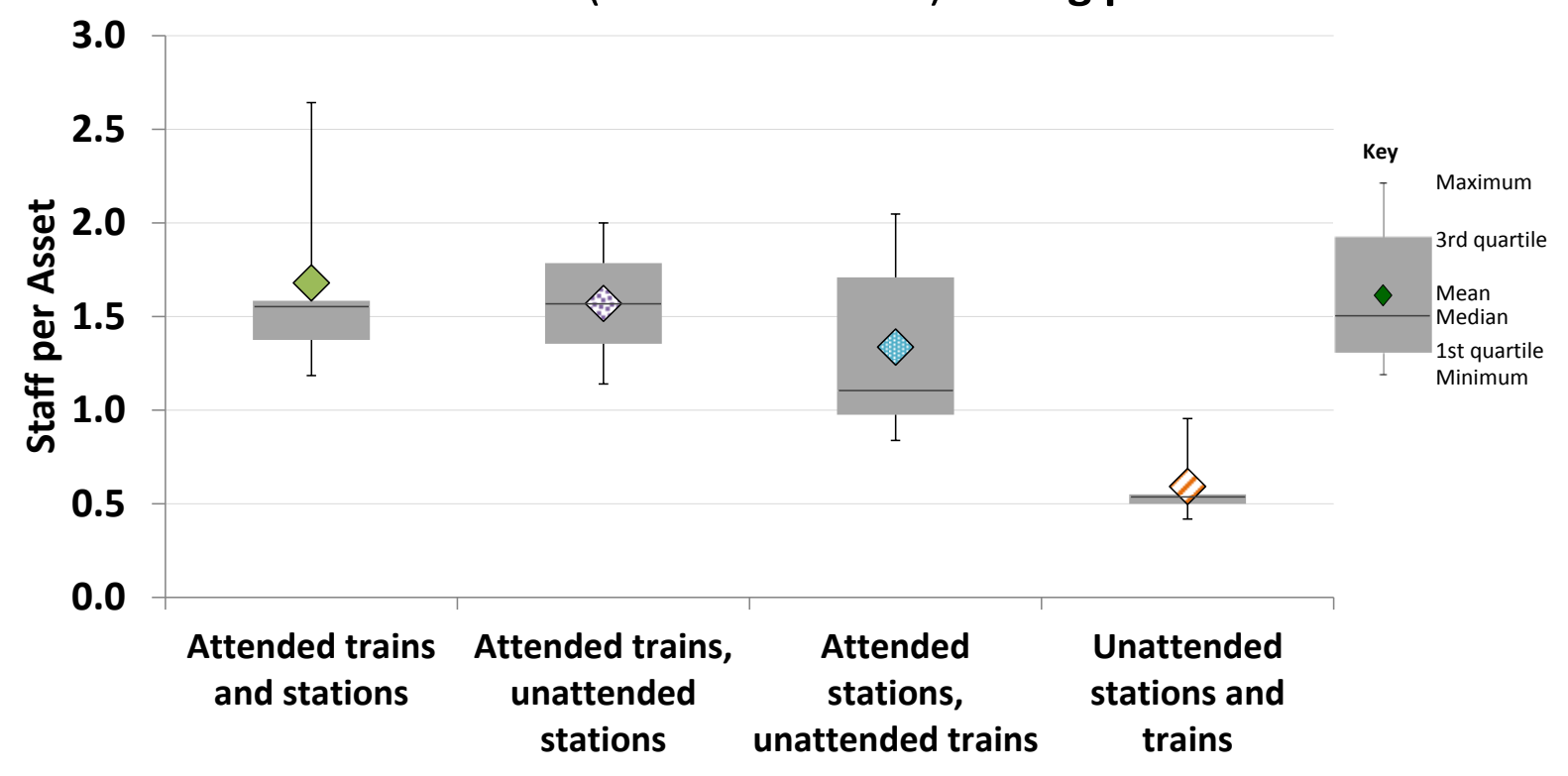

FIGURE 5 Effect of staffing model on staff per asset 
JM Cohen*, AS Barron, RJ Anderson, \& DJ Graham

Peak hour train frequencies of GoA4 lines compared with all line frequency data available from CoMET and Nova metros

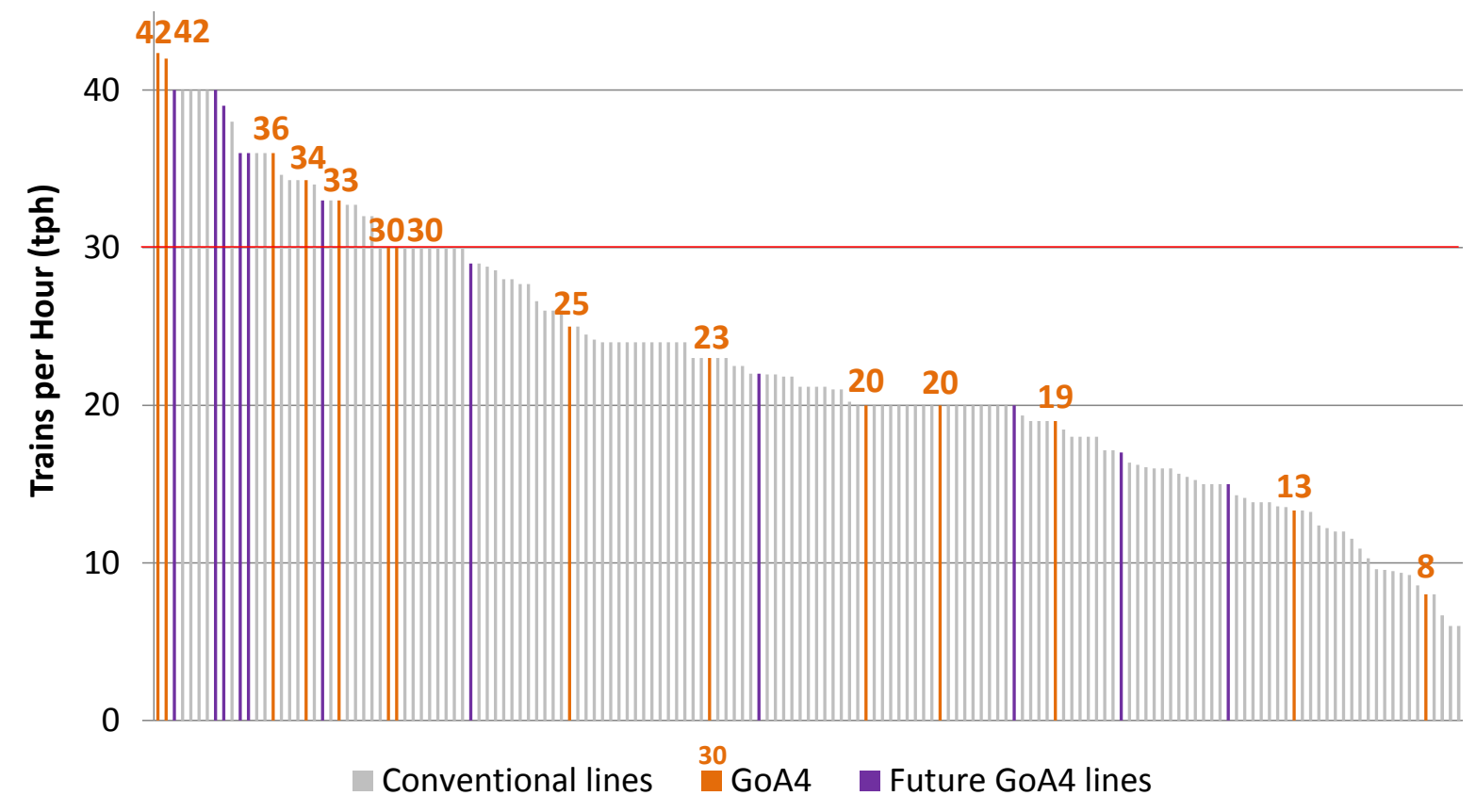

FIGURE 6 Service frequencies of existing and planned GoA4 lines 
Million train-km between incidents of $>5$ minutes duration:

Whole networks and automated lines (2012)

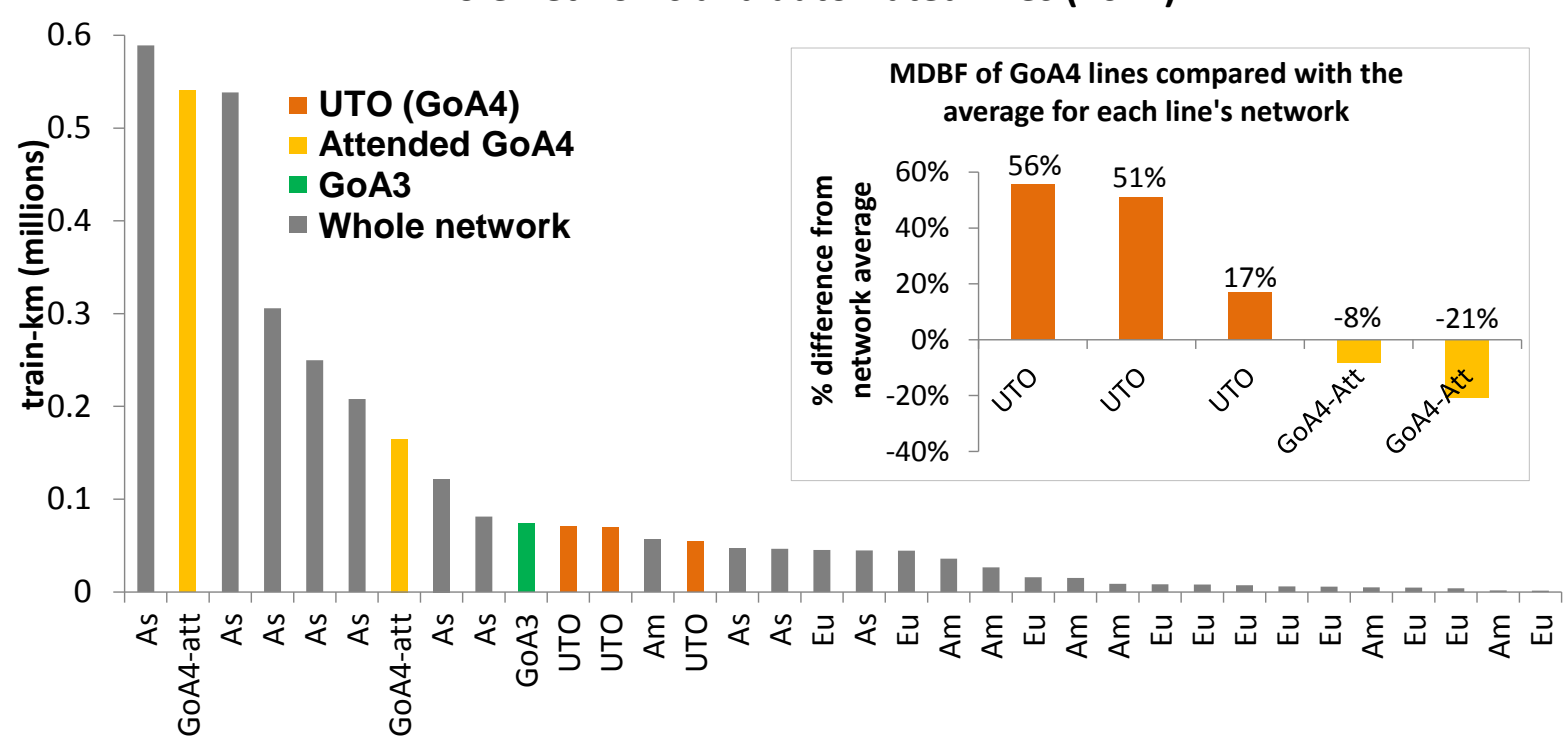

FIGURE 7 Reliability of Automated Lines Compared with Whole Metro Networks 